\title{
Human Capital Convergence: Evidence from the Punjab
}

\section{Uzma Afzal ${ }^{*}$}

\begin{abstract}
While the literature on economic growth provides mixed evidence on convergence across different countries and regions, a large number of studies point toward the widening income gap between rich and poor. In the development literature, a broader range of national welfare indicators beyond income per capita-health and education in particular-are considered important instruments for measuring progress in human development. This article examines education and other selective welfare indicators to determine if there has been unconditional and conditional convergence across the districts of Pakistani Punjab over the period 1961-2008. The study can be considered part of the growing literature that looks at growth theory in developing countries in the context of human capital. Thus far, few studies have examined human capital in the context of convergence, and Pakistan has not been studied in any depth up to now. The results of our empirical analysis show that over the last five decades, both unconditional and conditional convergence has taken place in literacy rates across Punjab, and that this has been accompanied by increased gender parity in educational enrolment levels and improved housing conditions.
\end{abstract}

Keywords: Human capital, unconditional convergence, conditional convergence, Pakistan.

JEL Classification: I31, R10.

\section{Introduction}

The variations in countries'/regions' economic performance has fueled the debate on convergence in their growth rates to determine if initially disparate countries/regions are converging to common steadystate levels. The literature on economic growth provides mixed evidence on this, and many studies point toward the widening income gap between rich and poor. In the development literature, a broader range of national welfare indicators beyond income per capita-health and education in particular-are considered key instruments for measuring progress in

\footnotetext{
* Senior Research and Teaching Fellow, Centre for Research in Economics and Business (CREB), Lahore School of Economics, Pakistan.
} 
human capital development. With the rising divergence of income levels across the world, it is pertinent to ask whether such divergence is also occurring in the different aspects of human development.

This study examines three human development indicatorshousing, education, and health-to determine if there has been convergence across the districts comprising Pakistani Punjab over the period 1961-2008. It also focuses on convergence in education outcomes across gender to determine if the gaps between male and female enrolment levels have changed over the last six decades. The study is effectively part of the growing agenda to investigate concepts of growth theory in developing countries in the context of human capital. Given that income per capita alone is not sufficient to determine people's welfare status, by looking at convergence in social welfare indicators we attempt to study development in a new light. Few studies have examined human capital in the context of convergence and Pakistan has not been studied in depth in any such work; this study is, therefore, among the first to do so.

There is growing concern that regional inequality in Pakistan has worsened over the past few decades (Abbas \& Foreman-Peck, 2008; Khan, 2001). Inequitable growth has also been a cause of concern for other developing countries such as China and India. As Pakistan's largest and most diverse province, Punjab has been criticized for holding the majority of the country's wealth compared to other provinces and, within Punjab, the unbalanced division of resources has fueled the call for Punjab to be divided into new, smaller provinces.

A number of studies on Pakistan find that the intensity of poverty increases as one moves toward the southern and western regions. Literacy rates and enrolment levels, along with access to basic public goods such as electricity, gas, and sanitation, are far lower in the southern and western districts than elsewhere (Cheema, Khalid, \& Patnam, 2008; Khan, 2009). Afzal (2010) shows that patterns of human welfare across Punjab have persisted over the last five decades, and concludes that less developed districts have been unable to break out of their lagging status. Whether these gaps among Punjab's districts have increased or decreased, however, remains unexplored.

The article is organized as follows: Section 2 provides an overview of the literature on growth and human capital convergence. Section 3 puts forward a theoretical understanding of the concept and types of convergence. Section 4 describes the data used and presents the study's 
results for convergence in Punjab. Section 5 provides a brief conclusion drawing on the estimates presented in Section 4.

\section{A Brief Review of the Literature}

The growth literature comprises numerous cross-country studies and, more recently, intra-country studies that explore initially disparate regions that converge to common steady-state paths (see Barro, 1991; Barro \& Sala-i-Martin, 1991; Baumol, 1986; Button \& Pentecost, 1995; De Long, 1988; Jian, Sachs, \& Warner, 1996; Jones, 1997; Maasoumi \& Wang, 2008; Mankiw, Romer, \& Weil, 1992; Pritchett, 1997; Sachs, Bajpai, \& Ramiah, 2002; Trivedi, 2002). The pioneering work of Barro and Sala-i-Martin (1991) finds evidence of convergence across countries and, in the same notion Mankiw et al. (1992) observe convergence across countries by introducing other qualitative variables into their model.

The more recent literature portrays a different picture-that of rising growth rates accompanied by greater divergence across the world. According to Maddison (2001), in 1000 AD, Africa and western Europe had the same GDP per capita but, by 1998, the latter had become 13 times richer. Although developing countries such as China and India are rapidly closing in on the income gaps that separate them from the developed world, regional disparities have begun to emerge within the former.

The notion of wealth as the only indicator of welfare was contested centuries ago, and is still a matter of debate in some spheres. Over the years, development economists have kept pace with growth economists and produced studies exploring the importance of education and health in economic development. For most development economists, the quality of life is better determined by human and social capital rather than by simple measures such as per capita income/GDP. Kenny (2005) argues that income is considered important mainly because it is assumed to reflect the quality of life.

So, if incomes are diverging, then perhaps people's quality of life across different countries is also diverging. In studying this incomequality-of-life relationship, a number of economists have found that conventional wisdom does not hold true. Some studies have shown that income can account for a very small percentage of increase in people's social wellbeing (see Easterly, 1999; Preston, 1975). Easterly (1999) finds that most quality-of-life variables are not correlated with a country's growth rate and that its welfare indicators may actually have been improving over the past few decades. 
According to Kenny (2005), most analyses on the issue of relative growth in quality-of-life variables find evidence of convergence. Numerous studies also confirm the significance of education and health in the development process. In a cross-country study, de Babini (1991) examines the enrolment level, participation of women in education, and certain school indicators for the period 1960-1983. By looking at the coefficient of variation $(\mathrm{CV})$ in a sample of over 100 countries, she finds convergence across all levels of education.

Ingram (1992) looks at a large sample of developed and developing countries and finds that the gaps in per capita GDP have increased among low-, middle-, and high-income countries. The author finds evidence of strong convergence across the sample for most social indicators in the analysis-life expectancy, caloric intake, primary enrolment ratio, and urbanization. Using data from 84 countries for 19701990, Sab and Smith (2002) ask whether health and education levels are converging across countries. They conclude that investments in education and health are closely linked, and that there is unconditional convergence for life expectancy, infant survival, and average levels of schooling in the adult population.

\section{Two Concepts of Convergence}

Drawing on the vast and burgeoning literature on growth, there are two main concepts of convergence: $\beta$-convergence and $\sigma$-convergence (Barro \& Sala-i-Martin, 1995). The first applies if a poor country tends to grow faster than a rich country such that it catches up with the latter in terms of per capita income. Simply put, $\beta$-convergence assumes that initially poor countries tend to grow faster than rich ones. The key assumption generating from the neoclassical model is that of diminishing returns to reproducible capital, thus economies with lower stocks of physical capital will enjoy higher marginal rates of return on capital (Trivedi, 2002).

$\beta$-convergence has two forms: (i) conditional, and (ii) unconditional/absolute. Conditional convergence suggests that convergence depends on an economy's structural characteristics-those factors causing changes in its steady state-and that these structural differences mean that different countries will have different steady states relative to their per capita incomes (Lall \& Yilmaz, 2000). Introducing additional structural variables into the basic growth regression can be used to test this. 
A stronger kind of convergence takes place unconditionally or absolutely when initially poorer states grow faster, albeit under different initial conditions. With reference to the Solow model, if we assume that all regions in the long run have no tendency to show differences in the rates of investment, capital depreciation, population growth, and human capital formulation, etc., then such a model will result in unconditional convergence to a common value of per capita income (Trivedi, 2002). The assumptions behind unconditional convergence, however, might better fit regional datasets where different regions within a country are more similar than different countries with respect to technology and preferences (Barro \& Sala-i-Martin, 1995).

The concept of $\sigma$-convergence concerns cross-sectional dispersion, and occurs if the dispersion of a particular indicator across a region declines over time (Barro \& Sala-i-Martin, 1995). It can be measured by looking at the size of the standard deviation (SD) of the selected variable: A fall in the SD will imply convergence across the region over time. The $\mathrm{CV}$ is the ratio of the SD to the mean, and measures convergence relative to the mean; it is useful where variables are expected to trend upward across the world over time (Kenny, 2005). Barro and Sala-i-Martin (1995) argue that $\beta$ convergence (where poor countries tend to grow faster than rich ones) leads to $\sigma$-convergence, but that this process can be offset by new disturbances that tend to increase dispersion.

We will study human capital convergence, following the methodology of Trivedi (2002) and Sab and Smith (2001), who essentially adapt the basic framework laid down by Mankiw et al. (1992). The methodology is better explained by taking the example of an indicator that is included among the variables being analyzed in this article. Let us say that we are testing for convergence in literacy rates across the districts of Punjab:

$$
\ln \left(l i t_{i, t}\right)-\ln \left(l i t_{i, t-\tau}\right)=\gamma \ln \left(l i t_{i, t-\tau}\right)+\sum_{j=1}^{k} \pi^{j} x_{i t-\tau}^{j}+\mu_{i}+\varepsilon_{i t}
$$

lit $t_{i t}$ is the literacy rate of district $i$ at time $t, x_{i t}$ is the set of conditioning variables that captures the differences in steady states, $\mu_{i}$ is the countryspecific fixed effect, $\varepsilon_{i t}$ is the error term that varies across regions and time periods and has a mean equal to 0 , and $\gamma$ is the convergence effect.

The difference in logs for literacy levels, which is the growth rate of literacy in the selected period, depends on the initial level of literacy and other complementary policies or endowments that may affect the growth 
of literacy rates. To test for absolute convergence, we do not control for steady-state determinants, and only the initial literacy levels appear on the right-hand-side. To control for heteroscedasticity of unknown form, we use robust standard errors alongside ordinary least squares estimates.

\section{Testing for Human Capital Convergence}

\subsection{Data and Descriptive Statistics}

This study draws on data from three sources: (i) the district census reports for 1961, 1981, and 1998 (Government of Pakistan, n.d.); (ii) the Punjab Development Statistics (Government of the Punjab, 1981, 2000); and (iii) the Multiple Indicator Cluster Survey (MICS) for 2007/08 (Government of the Punjab, 2008). The district census reports are among the earliest reports available at the district level; since the 1998 census was the last national census conducted, data for Punjab for 2008 is obtained from the MICS for $2007 / 08$. The MICS is a cross-sectional micro-level dataset consisting of 91,075 households and 592,843 listed members.

Type of shelter and living conditions determine people's social and economic wellbeing. To gauge this, we include average household size, the number of rooms per housing unit, percentage of houses with brick (pakka) walls, and percentage of houses with reinforced (pakka) roofs. ${ }^{1}$

Next, we consider several education indicators: Male and female literacy rates (for persons aged 10 or above); gross enrolment rate (the number of students enrolled at a given level, regardless of their age, and expressed as a percentage of the corresponding eligible age group population for each level of education; ${ }^{2}$ and enrolment rates at the primary, secondary, and tertiary level for both genders.

Due to the unavailability of output variables for health at the district level, we include variables that help determine the accessibility of health services: Hospitals per 10,000 population, and the number of patients treated as a percentage of the total population. Information on patients treated and the number of total hospitals and dispensaries in each district for 1981 and 1998 has been taken from the Punjab Development Statistics (see Government of the Punjab, 1981, 2000).

\footnotetext{
${ }^{1}$ Pakka walls are constructed of brick or stone, and are cement-bonded. Pakka roofs are made of reinforced concrete and cement (RCC), reinforced brick and cement (RBC), or girder/beam and baked bricks.

${ }^{2}$ The age bracket for each level of education is: primary (5-9 years), secondary (10-14 years), and tertiary (15-24 years).
} 


\subsection{Estimating $\sigma$-Convergence}

Table 1 presents descriptive statistics for the 1961-2008 data being used, including the mean, SD, and CV for the variables explained above. The changes in mean simply show whether there has been an overall change in the prevalence level of each of the variables; means testingconducting a t-test on the values for two different years-allows us to determine if two means are statistically different from one other.

The SD, also known as $\sigma$-convergence, is the preferred measure of convergence if the absolute differences in a variable are considered the most important. The CV measures convergence relative to the mean and is more pertinent when absolute increases in the mean level are expected (Kenny, 2005). If all countries undergo similar absolute increases in an indicator, this would leave the SD unchanged, but it would overlook the decline in percentage differences across countries. The CV is unit-less, and therefore the choice of unit of measurement does not affect its size (Kenny, 2005). For this study, since the social indicators are expected to follow an upward trend during the selected period, the $\mathrm{CV}$ is considered a better instrument for measuring convergence.

In terms of housing indicators, the mean household size has increased from about five persons per household to seven. This reflects the dramatic increase in population in Punjab, even though the SD and CV both reflect divergence across the districts. If we examine these results and the data, the divergence implies that household size in the districts has increased but at different rates, i.e., in some districts, household size has increased much faster than in others. 
Table 1: Descriptive statistics

\begin{tabular}{lrrrrrr}
\hline & \multicolumn{2}{c}{ Mean a } & \multicolumn{2}{c}{ SD b $^{\text {b }}$} & \multicolumn{2}{c}{ CV c } \\
\cline { 2 - 7 } Indicator & $\mathbf{1 9 6 1}$ & $\mathbf{2 0 0 8}$ & $\mathbf{1 9 6 1}$ & $\mathbf{2 0 0 8}$ & $\mathbf{1 9 6 1}$ & $\mathbf{2 0 0 8}$ \\
\hline Average household size & $5.40^{*}$ & $6.50^{*}$ & 0.24 & 0.34 & 4.4 & 5.3 \\
Rooms per housing unit & $1.80^{*}$ & $2.08^{*}$ & $0.34^{*}$ & $0.13^{*}$ & 19.5 & 6.1 \\
Households with pakka walls (\%) & $21.40^{*}$ & $73.20^{*}$ & 14.00 & 19.10 & 65.6 & 26.1 \\
Households with pakka roofs (\%) & $7.50^{*}$ & $82.50^{*}$ & $4.14^{*}$ & $13.60^{*}$ & 55.9 & 16.5 \\
Literacy rate (male) & $20.00^{*}$ & $68.60^{*}$ & 7.40 & 10.40 & 37.1 & 15.1 \\
Literacy rate (female) & $5.57^{*}$ & $47.40^{*}$ & $3.40^{*}$ & $13.60^{*}$ & 60.7 & 28.8 \\
Primary enrolment rate (male) & $35.70^{*}$ & $103.30^{*}$ & 11.8 & 12.80 & 33.0 & 12.4 \\
Primary enrolment rate (female) & $17.40^{*}$ & $95.30^{*}$ & $3.40^{*}$ & $19.80^{*}$ & 47.3 & 20.8 \\
Secondary enrolment rate (male) & $27.10^{*}$ & $49.50^{*}$ & 9.52 & 18.90 & 35.1 & 38.2 \\
Secondary enrolment rate (female) & $6.20^{*}$ & $66.80^{*}$ & $4.90^{*}$ & $16.10^{*}$ & 79.4 & 24.2 \\
Tertiary enrolment rate (male) & $0.71^{*}$ & $10.30^{*}$ & $0.50^{*}$ & $2.40^{*}$ & 69.9 & 23.6 \\
Tertiary enrolment rate (female) & $0.19^{*}$ & $10.33^{*}$ & $0.28^{*}$ & $3.86^{*}$ & 148.0 & 37.4 \\
Patients treated & $0.44^{*}$ & $0.0008^{*}$ & 0.07 & 0.05 & 27.2 & 25.1 \\
Hospitals per 10,000 population & $0.369^{*}$ & $0.0236^{*}$ & $0.12^{*}$ & $0.00002^{*}$ & 19.8 & 21.4 \\
\hline
\end{tabular}

Notes: Asterisk * indicates significance at 1 percent.

a P-values are based on the t-test for the significance of two means, where the null hypothesis states that the value of the ratio of the 2008 to 1961 mean is unity (against a two-tailed alternative)

b P-values are based on the variance ratio test, where the null hypothesis states that the value of the ratio of the 2008 to 1961 standard deviation is unity (against a two-tailed alternative)

c The coefficient of variation $(\mathrm{CV})$ is the ratio of the standard deviation (SD) to the mean.

Source: Author's calculations.

The average number of rooms in a household has also increased across Punjab and the CV would suggest that there has been convergence across the districts. The percentage of households with pakka walls and roofs has increased several-fold, reflecting improved living conditions across all the districts. Although the SD has increased for both these variables, ${ }^{3}$ we are interested in the results for the $C V$, in which there is no clear decline for houses with pakka walls and roofs. This implies that the overall structure of housing across Punjab has improved and that people are gravitating away from mud structures and inadequate shelter.

Male and female literacy rates are fundamental measures of human capital development. Both have increased considerably in Punjab, which

\footnotetext{
${ }^{3}$ The disparity in the results for SD and CV is also common in other studies (see Sab \& Smith, 2001).
} 
could reflect the cumulative impact of the education policy in previous years. From Table 1, we can see that, with rising literacy levels, there is also convergence in literacy rates across districts. Enrolment rates at all levels of education have risen dramatically. Both male and female primary enrolment rates have increased in volume, while the gaps between districts have declined over the same period. The female secondary enrolment rate follows the same trend and shows rapid improvement and convergence across the districts. Male secondary enrolment levels, however, show an overall increase but greater divergence across districts. Tertiary enrolment levels are nominal at the start of 1961 but have increased several-fold by 2008. A 10-percent tertiary enrolment rate is not impressive by international standards, but there has been improvement over the last four decades. The CV for the tertiary enrolments rate has also declined.

The two health indicators in the table show a decline in the mean levels from 1961 to 2008. Since the population has increased considerably over the given period and both indicators are a ratio of the population, the declining mean levels are not surprising. It also reflects the fact that the increase in health facilities in Punjab has not kept pace with the rise in number of people. Convergence across districts becomes trivial, therefore, when the entire province needs massive investments in health facilities across the board.

\subsection{Estimating $\beta$-Convergence: Absolute or Conditional?}

We also check to see if the second kind of convergence- $\beta$ convergence-also exists across districts of Punjab. We have a range of instruments with which to measure education-our variable of interestand will therefore use it to gauge human capital. Since there is insufficient information on outcome variables for health, they will be discussed briefly along with housing variables.

\subsubsection{Absolute/Unconditional Convergence}

To examine unconditional convergence in a regression framework, The estimated model takes the following form:

$$
\ln Y_{i, 1961-2008}=\text { constant }+\gamma(\ln Y)_{i, 1961}+\varepsilon_{i}
$$

A negative and significant value for $\gamma$ implies unconditional or absolute convergence to a common steady state. Simply, a region with an initially lower level in a variable will experience higher growth in that variable. 
Table 2 reports our estimates, with the results for four different periods presented in each column. The independent variable for each regression takes the value that prevailed at the start of the period. So, in column 1, the independent variables take the values of the year 1961 and the dependent variable is the average growth in the variable over the period 1961-2008. A negative and statistically significant value for the coefficient $\gamma$ implies absolute convergence to a common steady state (Trivedi, 2002). From the results we can see that all the housing variables have significant negative coefficients, implying that there has been absolute convergence across all districts over the 50 -year period.

Our estimates for male and female literacy rates for the period 1961-2008 by decade produce very encouraging results. With every successive decade, the lagging districts appear to close the gap between the more literate districts. The gender parity index measures female enrolment rates as a ratio of male enrolment rates to determine the parity between the sexes across education levels. The results for the gender parity index show that, for all three levels of education in Punjab, there has been unconditional convergence for the majority of estimates.

Overall, for the period 1961-2008, our results appear to strongly point toward a converging Punjab where female enrolment levels are catching up with male enrolment levels. Some exceptions exist in estimates by decade where some results emerge as not being statistically significant. Male and female enrolment rates at all levels have negative coefficients, which implies that there has been unconditional convergence in Punjab across all levels of education. 
Table 2: Unconditional convergence

\begin{tabular}{|c|c|c|c|c|}
\hline \multirow{2}{*}{$\begin{array}{l}\text { Independent variable } \\
\text { (Initial period) }\end{array}$} & \multicolumn{4}{|c|}{ Estimated coefficient } \\
\hline & 1961-2008 & 1961-81 & 1981-98 & 1998-2008 \\
\hline Average household size & $\begin{array}{l}-0.216^{* * *} \\
(-0.227)\end{array}$ & - & - & - \\
\hline Rooms per housing unit & $\begin{array}{l}-0.752^{* * *} \\
(0.059)\end{array}$ & - & - & - \\
\hline Households with pakka walls (\%) & $\begin{array}{l}-0.629^{* * *} \\
(0.059)\end{array}$ & - & - & - \\
\hline Households with pakka roofs (\%) & $\begin{array}{l}-1.020^{* * *} \\
(0.079)\end{array}$ & - & - & - \\
\hline Literacy rate (male) & $\begin{array}{l}-0.576^{* * *} \\
(0.041)\end{array}$ & $\begin{array}{l}-0.455^{* *} \\
(0.215)\end{array}$ & $\begin{array}{l}-0.406^{* * *} \\
(-0.089)\end{array}$ & $\begin{array}{l}-0.274^{* * *} \\
(0.026)\end{array}$ \\
\hline Literacy rate (female) & $\begin{array}{l}-0.551^{* * *} \\
(-0.058)\end{array}$ & $\begin{array}{l}-0.494^{*} \\
(0.236)\end{array}$ & $\begin{array}{l}-0.474^{* * *} \\
(0.156)\end{array}$ & $\begin{array}{l}-0.280^{* * * *} \\
(0.048)\end{array}$ \\
\hline Gender parity index (primary) & $\begin{array}{l}-0.728^{* * *} \\
(0.122)\end{array}$ & $\begin{array}{l}0.314 \\
(0.437)\end{array}$ & $\begin{array}{l}-0.742^{* * *} \\
(0.062)\end{array}$ & $\begin{array}{l}-2.416^{* * *} \\
(0.846)\end{array}$ \\
\hline Gender parity index (secondary) & $\begin{array}{l}-1.254^{* * *} \\
(-0.095)\end{array}$ & $\begin{array}{l}-0.405^{* * *} \\
(0.137)\end{array}$ & $\begin{array}{l}-0.418 \\
(0.259)\end{array}$ & $\begin{array}{l}-1.308^{* * *} \\
(0.129)\end{array}$ \\
\hline Gender parity index (tertiary) & $\begin{array}{l}-0.915^{* * *} \\
(0.065)\end{array}$ & $\begin{array}{l}-0.827^{* * *} \\
(0.109)\end{array}$ & $\begin{array}{l}-0.481^{* * *} \\
(0.117)\end{array}$ & $\begin{array}{l}-0.085 \\
(0.177)\end{array}$ \\
\hline Primary enrolment rate (male) & $\begin{array}{l}-0.699^{* * *} \\
(0.084)\end{array}$ & - & - & - \\
\hline Primary enrolment rate (female) & $\begin{array}{l}-0.380^{* * * *} \\
(0.084)\end{array}$ & - & - & - \\
\hline Secondary enrolment rate (male) & $\begin{array}{l}0.049 \\
(0.092)\end{array}$ & - & - & - \\
\hline Secondary enrolment rate (female) & $\begin{array}{l}-0.750^{* * *} \\
(0.078)\end{array}$ & - & - & - \\
\hline Tertiary enrolment rate (male) & $\begin{array}{l}-0.840^{* * *} \\
(0.066)\end{array}$ & - & - & - \\
\hline Tertiary enrolment rate (female) & $\begin{array}{l}-0.828^{* * *} \\
(0.040)\end{array}$ & - & - & - \\
\hline Patients treated & $\begin{array}{l}-0.831^{* * *} \\
(0.244)\end{array}$ & - & - & - \\
\hline Hospitals per 10,000 population & $\begin{array}{l}-0.377 \\
(0.097)\end{array}$ & - & - & - \\
\hline
\end{tabular}

Notes: All estimates have been calculated using the logarithm of the dependent and independent variables - the dependent variable is the log difference of the independent variable in the given period.

Standard errors are given in parentheses. Asterisks ***,**, and * denote statistical significance at 1,5 , and 10 percent, respectively. We control for heteroscedasticity by controlling for robust standard errors when calculating estimates.

Source: Author's calculations. 
The only exception is the male secondary enrolment rate, the result of which is not statistically significant. The speed of convergence $(\lambda)$ for the male literacy rate is 0.018 , implying that it would take 38 years for this variable to move halfway to the steady state. ${ }^{4}$ For females, the speed of convergence is 0.017 , indicating that it would take about 41 years for the female literacy rate to move halfway toward its steady state. In terms of health indicators, the number of patients treated as a percentage of the total population converge unconditionally across Punjab, but the prevalence of hospitals per 10,000 people does not reflect any patterns of convergence since the coefficient is not significant.

\subsubsection{Conditional Convergence}

To measure conditional convergence in human capital across the districts of Punjab, we focus primarily on the outcome variables of education, i.e., literacy rates. As already stated in the previous sections, additional steady-state variables are introduced on the right-hand-side of Equation 2 to test for conditional convergence. The choice of these additional variables depends on economic theory, beliefs concerning the development process, the economic literature, and data availability (Sab \& Smith, 2001; Trivedi, 2002). In order to calculate estimates, we include household-level indicators to control for the steady-state level of literacy rates. Since our aim is to look for forces of convergence in the data rather than to test for a particular model of convergence or for the impact of control variables, we continue to focus on the coefficient of the literacy rate's initial level in Punjab. Table 3 presents the results from the estimates.

The coefficient of the male literacy rate for 1961 is negative and statistically significant at 1 percent, strongly suggesting the presence of conditional convergence across all districts of Punjab. Similarly, the coefficient of the female literacy rate for 1961 is significant and negative, also suggesting conditional convergence. The values for $\lambda$ are, in general, higher for conditional convergence results than those for unconditional convergence. Under conditional convergence, the male literacy rate moves halfway to the steady state in about 20 years, while the female literacy rate takes 26 years.

\footnotetext{
${ }^{4}$ The speed of convergence, $\lambda$, of a given variable is calculated by taking the negative of the natural $\log$ of 1 plus the coefficient of the lagged dependent variable divided by the period under observation. Thus, $\lambda,=-\ln (1+b) / \tau$ where $\tau$ is the period under analysis. The half-life, $t^{*}$, is the solution to $\mathrm{e}^{-\lambda^{*}}=0.5$. Taking logs of both sides, $\mathrm{t}^{*}=-\ln (0.5) / \lambda(\mathrm{Sab} \& \mathrm{Smith}, 2001)$.
} 
Table 3: Conditional convergence

\begin{tabular}{lcc}
\hline & \multicolumn{2}{c}{ Dependent variable: 1961-2008 } \\
\cline { 2 - 3 } Independent variable & Literacy rate (male) & Literacy rate (female) \\
\hline Literacy rate (male) 1961 & $-0.804^{* * *}$ & - \\
Literacy rate (female) 1961 & $(0.078)$ & $-0.709^{* * *}$ \\
& - & $(0.089)$ \\
Average household size & & -0.034 \\
& $-0.451^{*}$ & $(0.552)$ \\
Rooms per housing unit & $(0.248)$ & $0.459^{*}$ \\
& $0.316^{* *}$ & $(0.247)$ \\
Households with pakka walls (\%) & $(0.116)$ & 0.080 \\
& 0.043 & $(0.098)$ \\
Households with pakka roofs (\%) & $(0.039)$ & -0.035 \\
& 0.020 & $(0.044)$ \\
\hline
\end{tabular}

Notes: All estimates have calculated using the logarithm of the dependent and independent variables - the dependent variable is the log difference of the independent variable over the period 1961-2008.

Standard errors are given in parentheses. Asterisks ${ }^{* * *},{ }^{* *}$, and ${ }^{*}$ denote statistical significance at 1, 5, and 10 percent, respectively. We control for heteroscedasticity by controlling for robust standard errors when calculating estimates.

Source: Author's calculations.

This section has examined the hypotheses of unconditional and conditional convergence, following the neoclassical growth models. Education is a fundamental measure of human capital and the empirical results suggest the presence of both unconditional and conditional convergence in education and, therefore, in human capital.

\section{Conclusion}

We have examined patterns of human capital convergence across Punjab for the period 1961-2008. Since there are no major studies on the subject for Pakistan, let alone Punjab, we have compared our results with findings on other countries and regions. Given that the results on income convergence across countries are controversial, studies examining quality-oflife variables show their convergence almost unambiguously. On implementing the two main measurement techniques of convergence- $\sigma$ and $\beta$-convergence-we have found that most of the instruments of human capital and welfare in our data converge over the period 1961-2008. The average household size across Punjab's districts increases during the study period, implying that the population burden on national resources also rises. 
In testing for unconditional convergence, our results have shown convergence across household size, although the CV suggests otherwise; we cannot, therefore, conclusively suggest that this indicator shows signs of convergence. Moreover, housing conditions in Punjab have, overall, improved over time as concrete constructions are substituted for inadequate residential structures.

Gender parity across enrolment levels has increased, which means that more girls are now enrolled alongside boys. The primary enrolment rate for males, secondary enrolment rate for females, and tertiary enrolment rates for both genders have very high rates of convergence across districts. Since only one indicator - the number of patients treated as a percentage of the total population - of the two variables in our analysis shows signs of strong convergence, we cannot draw any significant conclusions concerning health.

The overall increase in literacy rates, gender parity, enrolment rates, and housing conditions are important achievements in themselves; that initially backward districts have caught up with more developed districts is an even more important achievement. This implies that the seemingly downtrodden districts of Punjab are not so disadvantaged when initial conditions are taken into context. It also implies that, with time, the gaps will continue to shrink should no major changes occur in the political economy.

That said, it should be pointed out that the average literacy and enrolment rates in Punjab and in Pakistan overall are not impressive in comparison with other developing countries with similar income levels. The positive trends and encouraging results brought out by this study do not allow for complacency, rather they advocate even greater effort on the government's part to invest in education and health. Greater provision of public health facilities and educational institutions is crucial to build on human capital development. Investment in these two sectors will consequently have positive spillovers on infant survival rates, spread of communicable diseases, and life expectancy.

Our findings also provide important insights into the growth process in Punjab. Keeping in mind the common perception that districts in Punjab have undergone both inequitable growth and division of national resources, the study's empirical results suggest that we can expect conditional income convergence eventually, given that human capital convergence is already underway in all other districts of the province. 


\section{References}

Abbas, Q., \& Foreman-Peck, J. (2008). Human capital and economic growth: Pakistan, 1960-2003. Lahore Journal of Economics, 13(1), 1-27.

Afzal, U. (2010). The changing profile of development: A historical study of the Punjab, 1961-2008 [Special edition]. Pakistan Development Review, 49(4).

Barro, R. J. (1991). Economic growth in a cross-section of countries. Quarterly Journal of Economics, 106(2), 407-443.

Barro, R. J., \& Salai-i-Martin, X. (1991). Convergence across states and regions. Brookings Papers on Economic Activity, 1, 107-182.

Barro, R. J., \& Sala-i-Martin, X. (1995). Economic growth. New York, NY: McGraw-Hill.

Baumol, W. J. (1986). Productivity growth, convergence, and welfare: What the long-run data show. American Economic Review, 76(5), 10721085 .

Button, K. J., \& Pentecost, E. J. (1995). Testing for convergence of the EU regional economies. Economic Enquiry, 33, 664-671.

Cheema, A., Khalid, L., \& Patnam, M. (2008). The geography of poverty: Evidence from the Punjab [Special edition]. Lahore Journal of Economics, 163-188.

De Babini, A.M.E. (1991). Convergence and divergence of education systems in today's world. Prospects, 21(3), 330-339.

De Long, J. B. (1988). Productivity growth, convergence, and welfare: Comment. American Economic Review, 78(5), 1138-1154.

Easterly, W. (1999). Life during growth. Journal of Economic Growth, 4(3), 239-276.

Ingram, G. (1992). Social indicators and productivity convergence in developing countries (Policy Research Working Paper No. 894). Washington, DC: World Bank. 
Jian, Y., Sachs, J., \& Warner, A. (1996). Trends in regional inequality in China. China Economic Review, 7(1), 1-21.

Jones, C.I. (1997). Convergence revisited. Journal of Economic Growth, 2, 131153.

Kenny, C. (2005). Why are we worried about income? Nearly everything that matters is converging. World Development, 33(1), 1-19.

Khan, A. (2009). Education order in Punjab: A district-level study [Special edition]. Pakistan Development Review, 48(4), 635-652.

Khan, M. A. (2001). Poverty reduction and human development: Issues and strategy. Lahore Journal of Economics, 6(2), 1-31.

Lall, S., \& Yilmaz, S. (2000). Regional economic convergence: Do policy instruments make a difference? Washington, DC: World Bank Institute.

Maasoumi, E., \& Wang, L. (2008). Economic reform, growth and convergence in China. Econometrics Journal, 11(1), 128-154.

Maddison, A. (2001). The world economy: A millennial perspective. Paris, France: Organisation for Economic Co-operation and Development.

Mankiw, G., Romer, D., \& Weil, D. (1992). A contribution to the empirics of economic growth. Quarterly Journal of Economics, 107(2), 407-437.

Preston, S. (1975). The changing relation between mortality and level of economic development. Population Studies, 29(2), 231-248.

Pritchett, L. (1997). Divergence, big time. Journal of Economic Perspectives, 11(3), 3-17.

Government of Pakistan. (n.d.). District census reports, 1961. Islamabad, Pakistan: Population Census Organization.

Government of Pakistan. (n.d.). District census reports, 1981. Islamabad, Pakistan: Population Census Organization.

Government of Pakistan. (n.d.). District census reports, 1998. Islamabad, Pakistan: Population Census Organization. 
Government of the Punjab. (1981). Punjab development statistics, 1981. Lahore, Pakistan: Punjab Bureau of Statistics.

Government of the Punjab. (2000). Punjab development statistics, 2000. Lahore, Pakistan: Punjab Bureau of Statistics.

Government of the Punjab. (2008). Multiple indicator cluster survey, Punjab: 2007-08. Lahore, Pakistan: Punjab Bureau of Statistics.

Sab, R., \& Smith, S. C. (2001). Human capital convergence: International evidence (Working Paper No. 01/32). Washington, DC: International Monetary Fund.

Sab, R., \& Smith, S. C. (2002). Human capital convergence: A joint estimation approach. International Monetary Fund Staff Papers, 49(2), 200-211.

Sachs, J. D., Bajpai, N., \& Ramiah, A. (2002). Understanding regional economic growth in India (Working Paper No. 88). Cambridge, MA: Harvard University, Center for International Development.

Trivedi, K. (2002). Regional convergence and catch-up in India between 1960 and 1992 (Working Paper No. 2003-W01). Oxford, UK: University of Oxford, Nuffield College. 